\title{
EKSPLORASI ETNOMATEMATIKA PADA GERABAH MLATEN
}

\author{
Isnaindah Jasmine Pertiwi ${ }^{1}$, Mega Teguh Budiarto ${ }^{2}$ \\ ${ }^{1,2}$ Universitas Negeri Surabaya, J1. Ketintang, Surabaya, Indonesia \\ Email: isnaindahpertiwi16030174077@mhs.unesa.ac.id
}

\begin{abstract}
Culture is used as a means to learn from everyday life. Mathematics can be associated with daily life, which can be learned through culture. The term mathematics in culture is called ethnomatematics. Each region has its own culture. In the village of Mlaten there is also a legacy that has been passed down, namely pottery with typical Majapahit carving. The purpose of this study is to explore the mathematical concepts contained in the Mlaten pottery, so that they can be used as learning resources in learning mathematics. This type of research is a qualitative research with an ethnographic approach. Data collection was carried out by means of literature study, observation methods, interview methods, and documentation methods. The instrument used is in the form of observation guidelines, interview guidelines, and documentation, it can be concluded that the mathematical concepts contained in the Mlaten earthenware are the concept of a circle, the concept of geometrical transformation, the concept of a flat shape, the concept of a curved side space, the concept of function, and the concept of the volume of objects rotate it. Ethnomatematics can make it easier for students to understand everyday problems.
\end{abstract}

Keyword: Ethnomathematics, Mathematicals concepts, Pottery

\begin{abstract}
Abstrak
Budaya dijadikan sebagai sarana untuk belajar dari kehidupan sehari-hari. Matematika dapat dikaitkan dengan kehidupan sehari-hari, yaitu dapat dipelajari melalui budaya. Istilah matematika dalam budaya disebut dengan etnomatematika. Setiap daerah memiliki budaya masing-masing. Di desa Mlaten juga ada warisan yang sudah turun temurun yaitu gerabah dengan ukiran khas Majapahit. Tujuan penelitian ini adalah untuk mengeksplorasi konsep matematika yang terdapat pada gerabah Mlaten, sehingga dapat dijadikan sumber belajar dalam pembelajaran metematika. Jenis penelitian ini adalah penelitian kualitatif dengan pendekatan etnografi. Pengumpulan data dilakukan dengan cara studi kepustakaan, metode pengamatan, metode wawancara, dan metode dokumentasi. Instrument yang digunakan yaitu berupa pedoman observasi, pedoman wawancara, dan dokumentasi, maka dapat disimpulkan bahwa konsep matematika yang terdapat pada gerabah Mlaten adalah konsep lingkaran, konsep transformasi geometri, konsep bangun datar, konsep bangun ruang sisi lengkung, konsep fungsi, dan konsep volume benda putar. Etnomatematika dapat mempermudah siswa memahami permasalahan sehari-hari.
\end{abstract}

Kata kunci : Etnomatematika, Konsep Matematika, Gerabah

\section{PENDAHULUAN}

Budaya adalah warisan tingkah laku simbolik kompleks berisi pengetahuan, kepercayaan, kesenian, moral, hukum dan adat istiadat, serta kemampuan yang didapatkan manusia sebagai anggota masyarakat. (Edward. 2002, Keesing. 2010). Mengutip dari Kluckhohn (1953) dalam, membagi unsur kebudayaan kedalam 7 unsur yaitu. Bahasa, merupakan alat komunikasi yang digunakan oleh anggota suatu masyarakat untuk bekerja sama, berinteraksi, dan mengidentifikasikan diri. Sistem teknologi atau Peralatan dan Perlengkapan Hidup Manusia, adalah segala sesuatu yang dibutuhkan oleh manusia dalam kehidupan sehari-hari seperti alat-alat produksi, makanan dan minuman, pakaian dan perhiasan, tempat berlindungm, dan alat-alat transportasi. Sistem mata 
pencaharian, merupakan sistem yang digunakan untuk manusia dalam memenuhi kebutuhan hidupnya terutama makanan seperti berternak, dan bertani. Sistem kemasyarakatan atau organisasi, adalah sistem yang tercipta dikarenakan kesadaran manusia, bahwa mereka masih memiliki kekurangankekurangan sehingga membutuhkan bantuan dari manusia lainnya dengan cara mereka harus hidup dan bergaul. Kesenian, merupakan tempat manusia bebas berekspresi dan meluapkan kreatifitasnya. Kesenian mengacu pada unsur keindahan yang berasal dari hati manusia. Sistem pengetahuan, secara sederhana dapat diartikan sebagai segala sesuatu yang diketahui manusia tentang benda, sifat, keadaan, dan harapan-harapan. Sistem kepercayaan atau sistem religi, adalah suatu sistem, dimana manusia percaya terhadap sesuatu yang dianggap lebih tinggi darinya.

Matematika adalah mata pelajaran wajib yang diajarkan disetiap jenjang sekolah. Namun, banyak siswa yang beranggapan bahwa matematika adalah pelajaran yang sulit (Hidayati, Isnani, \& Susongko, 2017). Pembelajaran kontekstual dapat membantu menangani kesulitan belajar matematika siswa (Fanany. 2019, Isnani. 2019). Budaya adalah suatu hal yang tidak bisa kita hidari dalam kehidupan sehari-hari, karena budaya adalah satu kesatuan yang menyeluruh dari beragam perwujudan perilaku dari masyarakat (Orey. 2000, Popa. 2018). Oleh karena itu pendidik memiliki pengaruh besar dalam membentuk batas-batas antara dua bidang yaitu matematika yang formal atau yang lebih sering disebut matematika yang ada di sekolah dan etnomatematika yang komprehensif kegiatan matematiika dalam kehidupan sehari-hari atau diluar sekolah. (Fouze. 2018, Hiebert\&Carpenter. 1992, Cimen. 2014).

Penelitian ini melakukan eksplorasi tentang gerabah Majapahit agar tidak mengalami kepunahan dan tetap terjaga kelestariannya. Eksplorasi atau penjelajahan (pencarian) adalah tindakan mencari atau melakukan penjelajahan dengan tujuan menemukan sesuatu (Koesoemadinata. 2000, Bates\&Jackson. 1980). Budaya atau peradaban adalah suatu hal yang tidak bisa kita hindari dalam kehidupan sehari-hari, karena budaya adalah satu kesatuan yang menyeluruh dari beragam perwujudan perilaku dari masyarakat (Edward. 2002, Koentjaraningrat.1985). Kebudayaan adalah seluru gagasan baik tidakan dan hasil karya manusia dalam kehidupan masyarakat yang dijadikan milik diri manusia sendiri dengan belajar (Koentjaraningrat. 1985, Edward. 2002). Kebudayaan juga dapat dinyatakan sebagai hasil karya manusia yang diwariskan dari generasi ke generasi melalui proses belajar dalam bentuk bahasa, sistem teknologi, sistem mata pencaharian, sistem kemasyarakatan, kesenian, sistem pengetahuan, sistem kepercayaan (Kluchkohn. 1953, Budiarto. 2019:5). Pixten (2014) menyatakan bahwa pada hakekatnya, matematika merupakan teknologi simbolis yang tumbuh pada keterampilan atau aktivitas lingkungan yang bersifat budaya. Hal tersebut memungkinkan bahwa konsep-konsep matematika yang ada dalam proses praktek-praktek budaya dan semua orang mengembangkan metode unik untuk memahami dan mengubah realitas mereka sendiri, yang kemudian disebut Etnomatematika (Orey. 2000, Fouze, 2018). Etnomatematika adalah kata yang diawali dengan "ethno" dan diakhiri dengan "mathematics" yang kemudian disebut dengan 
ethnomathematics, etnomatematika juga mengajarkan bagaimana matematika dihasilkan, ditransfer, dan disebarkan (D’Ambrosio.1985, Gerdes.1994, Pompeu.1994, Knijnik.1997, Bishop.1988, Budiarto. 2016). Peran etnomatematika dalam pembelajaran matematika sangat penting, etnomatematika masuk dalam kurikulum dan mempunyai peranan relative sama terhadap matematika. Selain itu etnomatematika dapat mempromotori lebih banyak budaya dan sekaligus untuk pembelajaran matematika (Budiarto. 2016, Richardo. 2016).
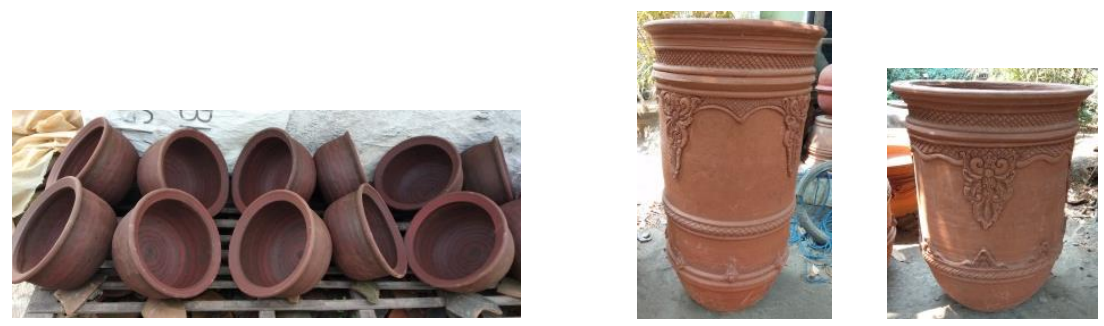

Gambar 1. Gerabah Mlaten

Gerabah Mlaten adalah hasil kerajinan asli dari Desa Mletan Kecamatan Puri Kabuten Mojokerto seperti yang dapat dilihat pada gambar 1. Awalnya pembuat gerabah mlaten adalah para orang tua terdahulu yang hingga sekarang ilmunya diturun kepada anak-anaknya. Gerabah mlaten milik pak ngataji ini terdapat ukiran mojopahit. Teknik yang digunakan ada tiga, yaitu teknik putar, teknik manual, dan teknik cetak. Untuk sekarang ini teknik yang digunakan adalah teknik putar, teknik manual, dan teknik cetak.
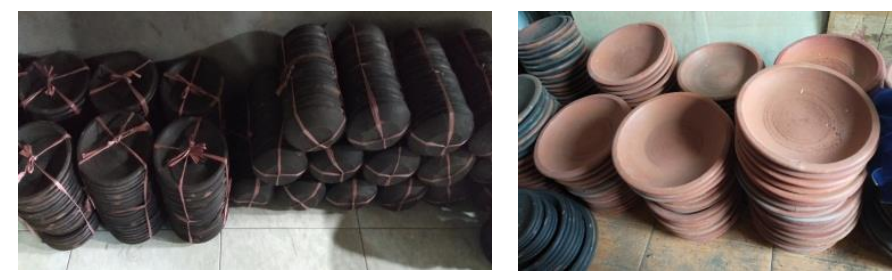

Gambar 2. Cobek khas desa Mlaten diproduksi dengan skala besar

Salah satu gerabah yang paling menonjol di desa Mlaten selain gerabah pak Ngataji adalah cobek. Cobek di desa Mlaten diproduksi dengan skala besar seperti pada Gambar 2.

Beberapa penelitian menunjukkan penerapan konsep matematika pada situs budaya dengan etnomatematika. Salah satunya yaitu penelitian dari Hardiati (2017) tentang etnomatematika : aplikasi bangun datar segiempat pada candi Muaro Jambi. Penelitian ini menunjukkan bahwa matematika dan budaya adalah dua hal yang saling berkaitan, dengan mengamati kawasan percandian candi Muaro Jambi, maka akan ditemukan konsep bangun datar segiempat pada beberapa bagian candi. Penelitian Lubis, dkk (2018) tentang eksplorasi etnomatematika pada alat music Gordang Sambilan. Hasil eksplorasi konsep matematika pada alat musik Gordang Sambilan berupa bentuk fisik yaitu konsep dasar geometri antara lain lingkaran, tabung, kerucut, dan kerucut terpancung. Konsep-konsep matematika yang terdapat pada alat music Gordang Sambilan dapat dimanfaatkan untuk mengenalkan matematika melalui budaya lokal. hal ini menunjukkan bahwa penerapan konsep matematika dapat melalui budaya lokal dan pembelajaran matematika akan lebih bermakna. Ada pula penelitian yang 
menjelaskan tentang etnomatematika menunjukkan bahwa matematika yang diajarkan dalam kehidupan sehari-hari berbeda dengan matematika yang diajarkan di dalam kelas. Salah satunya penelitian Putri (2017), yang telah meneliti eksplorasi etnomatematika kesenian rebana sebagai sumber belajar matematika pada jenjang MI. Penelitian ini menyajikan hasil eksplorasi bentuk etnomatematika yang bisa ditemukan pada kesenian bernuansa islami berupa alat music tradisional rebana. Penelitian Fajriyah (2018) yang telah meneliti peran etnomatematika terkait konsep matematika dalam mendukung literasi menyatakan bahwa etnomatematika memfasilitasi siswa untuk mampu mengkontruksi konsep matematika sebagai bagian dari literasi matematika berdasarkan pengetahuan siswa tentang lingkungan social budaya mereka. Selain itu, hasil penelitian Zayyadi (2017), telah meneliti eksplorasi etnomatematika pada batik Madura. Penelitian ini menghasilkan kesimpulan bahwa konsep-konep matematika (etnomatematika) pada motif batik Madura ini dapat digunakan dalam proses pembelajaran utamanya untuk memperkenalkan budaya.

Penelitian ini bertujuan untuk melestasikan budaya gerabah dan melestarikan budaya kerajaan Majapahit. Peran etnomatematika dalam pembelajaran matematika sangat penting, etnomatematika masuk dalam kurikulum dan mempunyai peranan relative sama terhadap matematika. Selain itu etnomatematika dapat mempromotori lebih banyak budaya dan sekaligus untuk pembelajaran matematika (Budiarto. 2016, Richardo. 2016). Maka tujuan penelitian ini juga dapat dijadikan literasi matematis berupa LKS berbasis etnomatematika eksplorasi gerabah khas Majapahit yang mengacu pada matematika kontekstual pada materi lingkaran. Penelitian ini membahas tentang eksplorasi etnomatematika, dimana matematika tidak hanya diajarkan di sekolah, melainkan matematika juga dapat di ajarkan dalam kehidupan sehari-hari. Pada penelitian ini juga akan dieksplorasi bagaimana konsep matematika yang diterapkan pada Gerabah. Penelitian ini dilaksanakan guna mendeskripsikan hasil eksplorasi bentuk etnomatematika dalam gerabah Mlaten, dan mendokumentasikan budaya gerabah Mlaten.

\section{METODE}

Penelitian ini menggunakan penelitian secara kualitatif dengan menggunakan pendekatan etnografi. Pendekatan etnografi yaitu pendekatan secara empiris dan teoritis yang bertujuan untuk mendapatkan deskripsi dan analisis tentang kebudayaan dengan penelitian lapangan (fieldwork) yang intensif (Spradley, 2007). Pendekatan etnografi ini dilakukan dengan cara pengambilan data secara sistematik mengenai cara hidup serta aktivitas social dan berbagai benda kebudayaan dari masyarakat (Endraswara, 2018). Dalam hal ini etnografi terkait tentang bagaimana suatu objek dirancang dan dibuat, sehingga dalam penelitian ini dipilih kebiatan yang belum banyak diketahui orang lain. Penelitian yang dilakukan bertujuan untuk menggali informasi tentang etnomatematika pada gerabah Mlaten yang meliputi konsep matematika pada gerabah. Informan dalam penelitian ini adalah pemilik usaha cobek yang masih aktif yaitu bapak Samiono, dan pengerajin gerabah bapak Ngataji. 
Pengumpulan data dilakukan dengan beberapa cara yaitu observasi, wawancara, dan dokumentasi. Analisis yang dilakukan adalah menganalisis bentuk matematika dan mengelompokkannya sesuai dengan konsep matematika yang ada.

\section{HASIL}

Berdasarkan dari hasil eksplorasi, desa Mlaten adalah desa penghasil gerabah khususnya cobek. Desa Mlaten terletak di kecamatan Puri, kabupaten Mojokerto, Jawa Timur, di desa ini terdapat banyak pengerajin cobek, salah satunya pengerajin cobek yang sudah lama menekuni pekerjaan ini adalah bapak Samiono. Beliau adalah pengerajin cobek yang sukses dan juga salah satu sesepuh Desa Mlaten. Proses pembuatan cobek tidak mudah, ada beberapa tahap yang perlu diperhatikan. Tahap pertama yaitu penghalusan tanah.

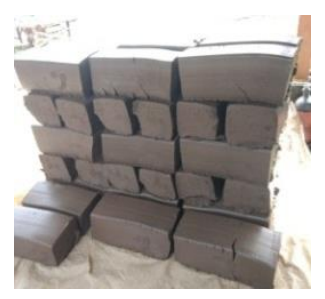

Gambar 3. Tanah yang sudah dihaluskan

Tanah yang akan dipakai membuat cobek dihaluskan terlebih dahulu hingga menjadi bongkahan-bongkahan berbentuk balok seperti pada Gambar 3.
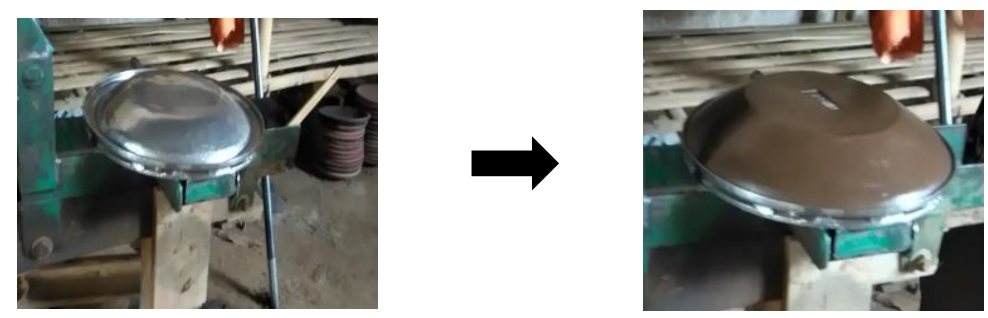

Gambar 4. Proses cetak cobek

Kemudian dilanjutkan dengan proses mencetak, prosesnya cukup singkat yaitu dengan cara ambil tanah yang sudah dihaluskan kemudian taruh pada cetakan yang sudah diberi minyak genteng terlebih dahulu seperti pada Gambar 4. Kegunaan minyak genteng ini agar saat proses mencetak cobek tidak ada tanah yang lengket pada cetakan. Kemudian press cetakan hingga cobek yang tercetak padat tidak ada gumpalan atau rongga.

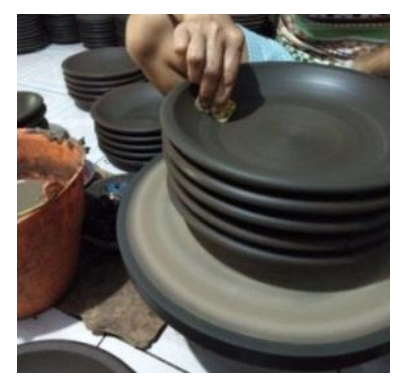

Gambar 5. Proses penghalusan dan pemberian warna 
Setelah dicetak, cobek diangin-anginkan di tempat yang teduh, sehingga kadar airnya berkurang. Kemudian cobek dihaluskan dan diberi warna seperti yang dapat dilihat pada Gambar 5 . Pewarna yang digunakan adalah pewarna genteng dengan warna merah bata. Setelah dihaluskan dan diberi warna, cobek diangin-anginkan lagi hingga terkikis. kemudian dihaluskan lagi agar terlihat mengkilap.

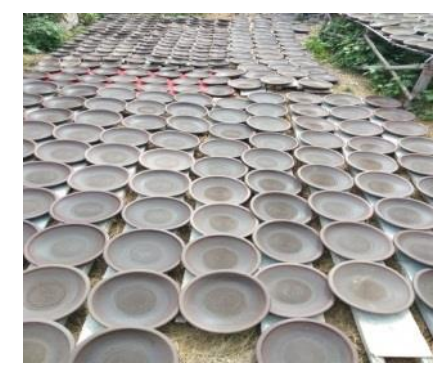

Gambar 6. Proses penjemuran

Setelah dihaluskan, cobek dijemur dibawah sinar matahari. Penjemuran cobek di bawah sinar matahari hingga kadar air pada cobek benar-benar habis seperti pada Gambar 6. Setelah terkikis kadar airnya, cobek dibakar selama 3-4 jam seperti pada Gambar 7. Setelah dibakar, cobek bersihkan dan beri kanji agar cobek terlihat mengkilap, cobek siap dipasarkan.
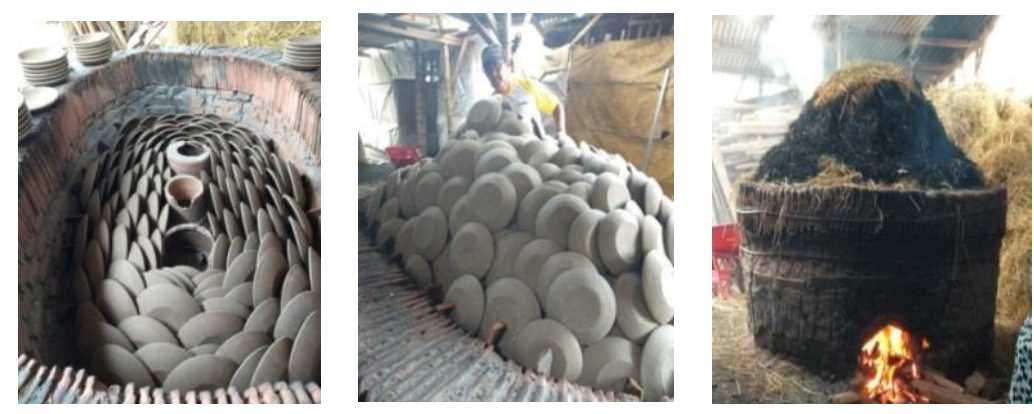

Gambar 7. Proses pembakaran

Berdasarkan hasil wawancara yang dilakukan peneliti terhadap informan yaitu bapak Samiono selaku sesepuh desa dan juga pembuat cobek khas Mlaten,. Pak Samiono mengatakan bahwa cobek dan gerabah di desa Mlaten sebenarnya sudah ada sejak dahulu, budaya membuat cobek sudah diturunkan dari orang tua terdahulu. Awalnya membuat cobek hanya digunakan untuk pekerjaan sampingan, tetapi sekarang cobek sudah menjadi mata pencaharian yang menjajikan. Cobek ini khas karena terbentuk dari tanah liat yang kuat, dan bahan yang awat dan tidak mudah pecah saat digunakan

Berdasarkan hasil eksplorasi, ada beberapa ukuran cobek berbeda, mulai $15 \mathrm{~cm}-30 \mathrm{~cm}$. Ukuran paling kecil diameter $15 \mathrm{~cm}$ disebut dengan Lepek, kemudian diatasnya diameter $20 \mathrm{~cm}$ disebut dengan Cowek, selanjutnya diameter $25 \mathrm{~cm}$ Tanggung, dan yang besar diameter $30 \mathrm{~cm}$ Layah. Ada juga ukuran terbesar yaitu Vigo dengan diameter $50 \mathrm{~cm}$, namun untuk pesanan yang sering diproduksi adalah Lepek, Cowek, Tanggung, dan Layah saja, sedangkan Vigo hanya dibuat saat ada 
pesanan saja karena ukurannya yang sangat besar. bentuk etnomatematika pada cobek khas Mlaten mengambil konsep matematika lingkaran dan konsep volume benda putar.

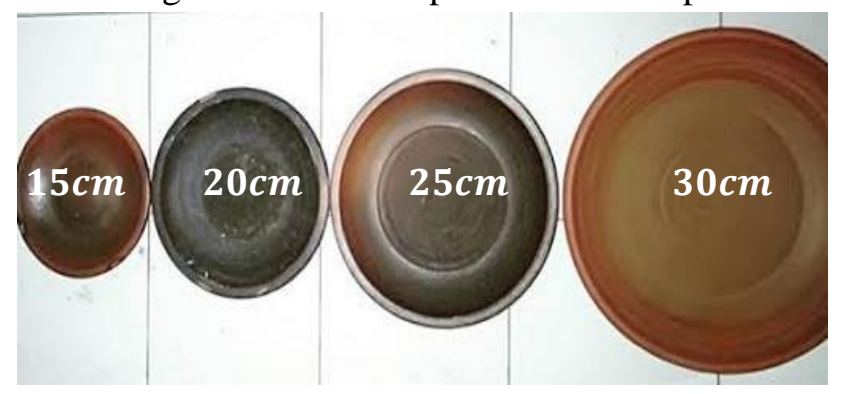

Gambar 8. Cobek dengan ukuran $15 \mathrm{~cm}-30 \mathrm{~cm}$

Cobek yang diproduksi di desa Mlaten ada beberapa ukuran diantaranya Lepek, Cowek, Tanggung, dan Layah, mulai dari ukuran $15 \mathrm{~cm}-30 \mathrm{~cm}$ seperti yang terdapat pada Gambar 8 . Tentunya dari keempat cobek tersebut memiliki ukuran diameter yang berbeda-beda antara lingkaran permukaan cobek dan lingkaran dasar cobek
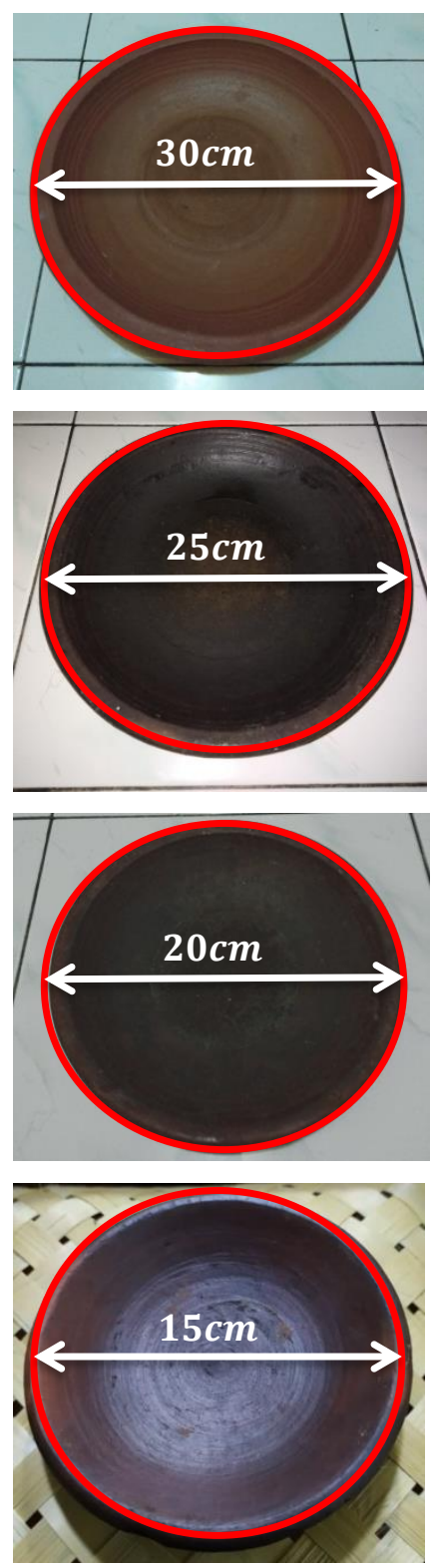
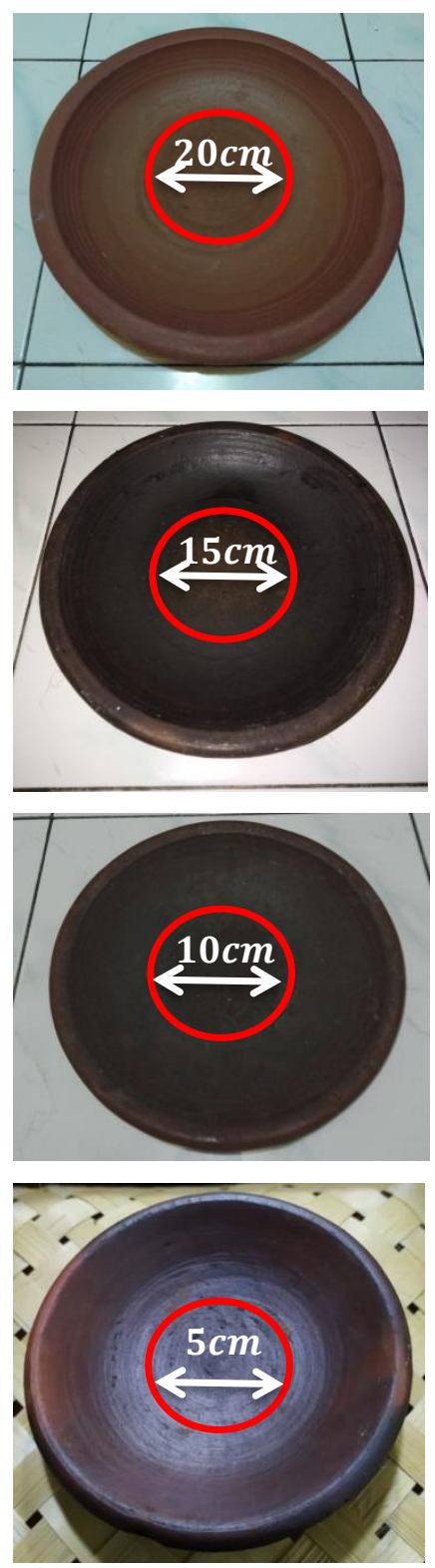

Gambar 9. Ukuran Lingkaran Cobek 
Selisih ukuran lingkaran cobek antara diameter pinggir cobek dan diameter dalam cobek adalah $10 \mathrm{~cm}$ dan itu berlaku sama untuk semua ukuran seperti yang terdapat pada Gambar 9. Seperti jika diameter pinggir $30 \mathrm{~cm}$ maka diameter dalam $20 \mathrm{~cm}$, jika deameter pinggir $25 \mathrm{~cm}$ maka diameter dalam $15 \mathrm{~cm}$, jika diameter pinggir $20 \mathrm{~cm}$ maka diameter dalam $10 \mathrm{~cm}$, dan jika diameter pinggir $15 \mathrm{~cm}$ maka diameter dalam hanya $5 \mathrm{~cm}$.

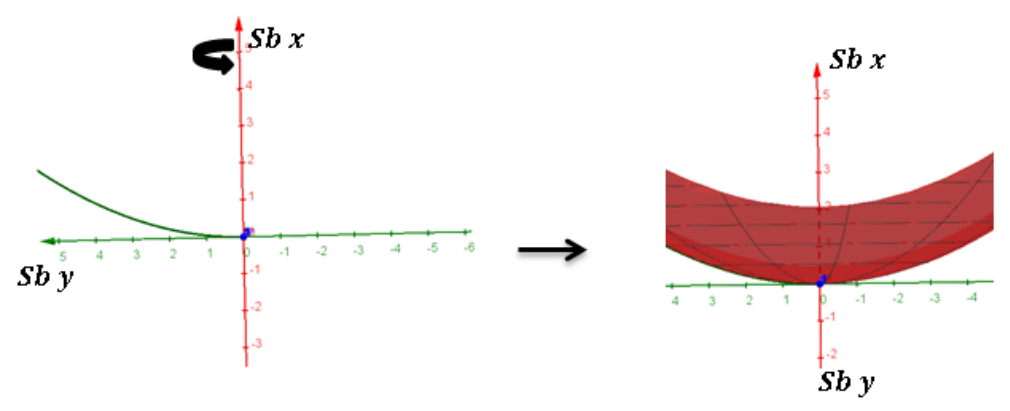

Gambar 10. Hasil sketsa Geogebra

Bentuk cobek yang dibuat tidak terlalu datar dan juga tidak terlalu melengkung seperti mangkuk. Bentuknya seperti piring tetapi sedikit lebih pipih. Bentuk seperti ini dapat diaplikasikan sebagai pembelajaran konsep benda putar yang diputar terhadap sumbu $x$ atau sumbu y seperti yang dapat dilihat dari Gambar 10.

Susanah(2014) mengatakan lingkaran adalah himpunan semua titik di bidang datar yang berjarak sama dari suatu titik tetap di bidang tersebut. Hasil eksplorasi menunjukkan bahwa cobek memiliki dua lingkaran yang berpusat pada satu titik yaitu titik senter. Dua lingkaran ini adalah lingkaran pinggir cobek dan lingkaran dalam cobek. Bentuk cobek seperti kurva parabola, Kristanto(2014) mengatakan bahwa kurva parabola terbentuk dari irisan sebuah kerucut. Hasil eksplorasi menunjukan bahwa bentuk dari cobek yang terlihat dari samping adalah bentuk kurva parabola. Berdasarkan hasil penelitian dan teori yang mendukung maka dapat dikatakan bahwa bentuk cobek adalah irisan kerucut dengan bentuk irisan lingkaran dan dua lingkaran yaitu lingkaran pinggir dan lingkaran dalam.

Selain Cobek, desa Mlaten juga mempunyai gerabah khas desa Mlaten dengan ukiran khas Majapahit. Berdasarkan hasil wawancara yang dilakukan peneliti terhadap informan yaitu bapak Ngataji selaku pengerajin gerabah khas Mlaten. Pak Ngataji mengatakan sejarahnya gerabah Mlaten ini sudah ada sejak dulu, kerajianan membuat gerabah sudah diajarkan secara turun menurun. Namun karena sekarang para sesepuh sudah meninggal semua, sekarang pak Ngataji dan anak-anaknya yang meneruskan warisan membuat gerabah ini. Ciri khasnya yaitu ukiran khas Majapahit pada gerabah yang dibuat. Cara membuat gerabah ini butuh kejelian, untuk gerabah yang sangat besar diawali dengan membuat cangkiran (dasar dari gerabah). kemudian lawungan, kemudian lambean (bibir pot atau kendi) dari gerabah bisa berbentuk pot bunga besar dan sebagainya. Kemudian baru dipercantik dengan ditambahi ukiran-ukiran. Teknik yang digunakan ada tiga, yaitu teknik putar, teknik manual, dan teknik cetak. Untuk menentukan senter pak Ngataji menggunakan kayu, pertama di ukur kayu 
dengan panjang tertentu kemudian, menentukan satu titik yang dijadikan pusat pada sebuah papan kayu. Lalu kayu yang sudah diukur tadi salah satu ujungnya diberi pensil, salah satu ujung kayu yang tidak ada pensil diletakkan tepat dititik yang dijadikan pusat. Kemudian kayu diputar sehingga goresan pensil membentuk suatu lingkaran yang senter.

Berdasarkan hasil eksplorasi, ada beberapa macam gerabah yang dibuat oleh pak Ngataji. Ada pot bunga, kendi, tempat payung, dan lain-lain. Gerabah yang dibuat juga ada berbagai macam ukuran sesuai dengan pesanan para pembeli.

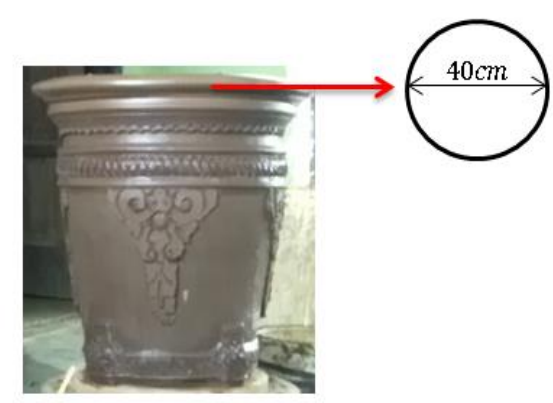

Gambar 11. Gerabah ukuran diameter $40 \mathrm{~cm}$ dan tinggi $60 \mathrm{~cm}$

Pot bunga dengan diameter $40 \mathrm{~cm}$ dan tinggi $60 \mathrm{~cm}$ seperti pada Gambar 11. Ada beberapa bentuk dari pot bunga ini yang dapat dijadikan bahan pembelajaran pada matematika. Salah satunya adalah konsep lingkaran, dapat digunakan sebagai penyusun soal mencari lingkaran yang berkaitan dengan kehidupan sehari-hari. Selain itu, ukiran pada pot bunga juga dapat dijadikan sebagai sarana pembelajaran konsep transformasi yaitu refleksi seperti pada Gambar 12.
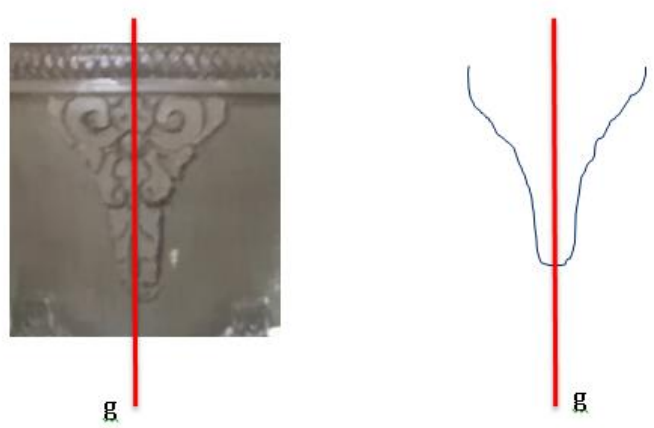

\section{Gambar 12. Gambar Ukiran Pada Gerabah}

Budiarto(2006) mengatakan refleksi adalah cerminan dari suatu objek dengan jarak dan ukuran yang sama. Hasil eksplorasi menunjukkan bahwa ukuran yang terdapat pada gerabah tersebut menggunakan konsep transformasi geometri yaitu refleksi, karena jika diambil satu garis tengah makan sisi kanan akan sama dengan sisi kiri.

Ada juga kendi untuk tempat menyimpan air. Kendi ini memiliki diameter $15 \mathrm{~cm}$. dari bentuk kendi, yang dapat dijadikan pembelajaran matematika adalah konsep lingkaran, dan fungsi. Dari kendi ini, dapat dilihat bahwa kurva yang terbentuk adalah kurva berbentuk parabola seperti pada Gambar 13. 


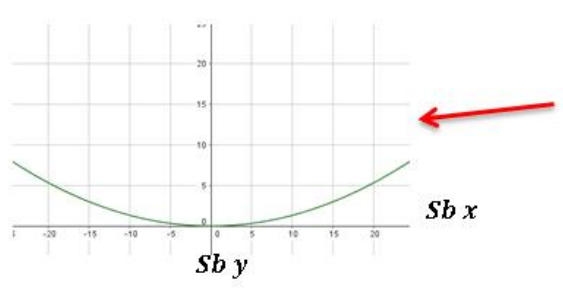

kurva parabola

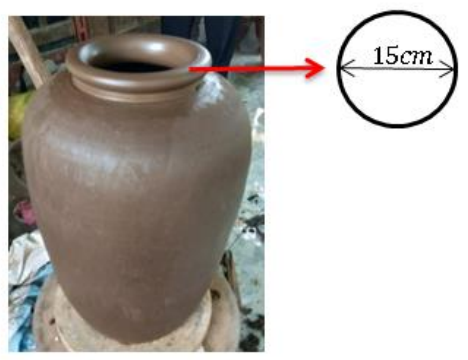

Gambar 13. Gambar Kendi Dan Hasil Sketsa Geogebra

Susanah(2014) mengatakan lingkaran adalah himpunan semua titik di bidang datar yang berjarak sama dari suatu titik tetap di bidang tersebut. Hasil penelitian menunjukkan visualisasi dari bibir gerabah yang rata-rata memiliki bentuk lingkaran. Kristanto(2014) mengatakan bahwa kurva parabola terbentuk dari irisan sebuah kerucut. Hasil penelitian gerabah kendi ini terlihat bahwa bentuk dari kendi tersebut adalah kurva parabola. Berdasarkan hasil eksplorasi dan teori yang terkait bentuk gerabah kendi adalah irisan dari kerucut dengan bentuk parabola dan dengan ditambahkan lingkaran sebagai bibir gerabah.

Tempat payung ini berukuran diameter $25 \mathrm{~cm}$ dan tinggi $40 \mathrm{~cm}$. tempat payung ini dapat dijadikan bahan ajar pada pembelajaran matematika untuk konsep bangun ruang sisi lengkung yaitu tabung dan konsep lingkaran seperti yang dapat dilihat pada Gambar 14.

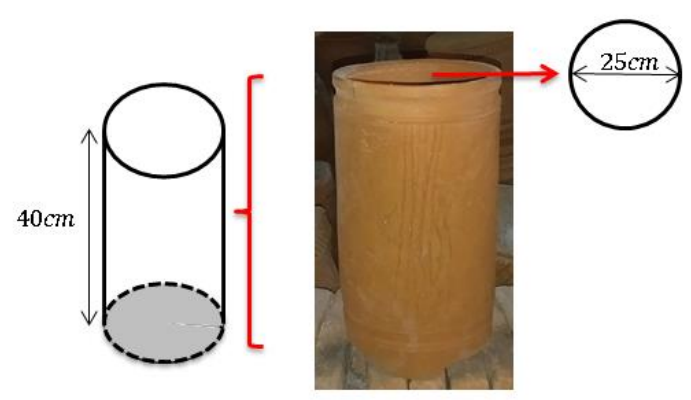

Gambar 14. Gerabah Tempat Payung Dan Sketsa Bangun Tabung

Downing(2009) mengatakan bahwa tabung adalah bangun yang dibentuk oleh gabungan semua ruas garis yang menghubungkan titik pada dua lingkaran yang kongruen dimana kedua lingkaran tersebut sejajar. Hasil penelitian pada tempat payung ini menunjukkan bahwa bentuk dari gerabah ini adalah tabung tanpa tutup. Berdasarkan hasil eksplorasi dan teori yang mendukung tempat payung ini memang memiliki bentuk tabung hanya saja salah satu ujungnya tidak tertutup.

Gerabah dengan ukuran diameter $50 \mathrm{~cm}$ dan tinggi $120 \mathrm{~cm}$ memiliki badan gerabah yang berbentu tabung, sedangkan untuk dasar gerabah yang menyerupai kurva para bola seperti yang dapat dilihat pada Gambar 15. 


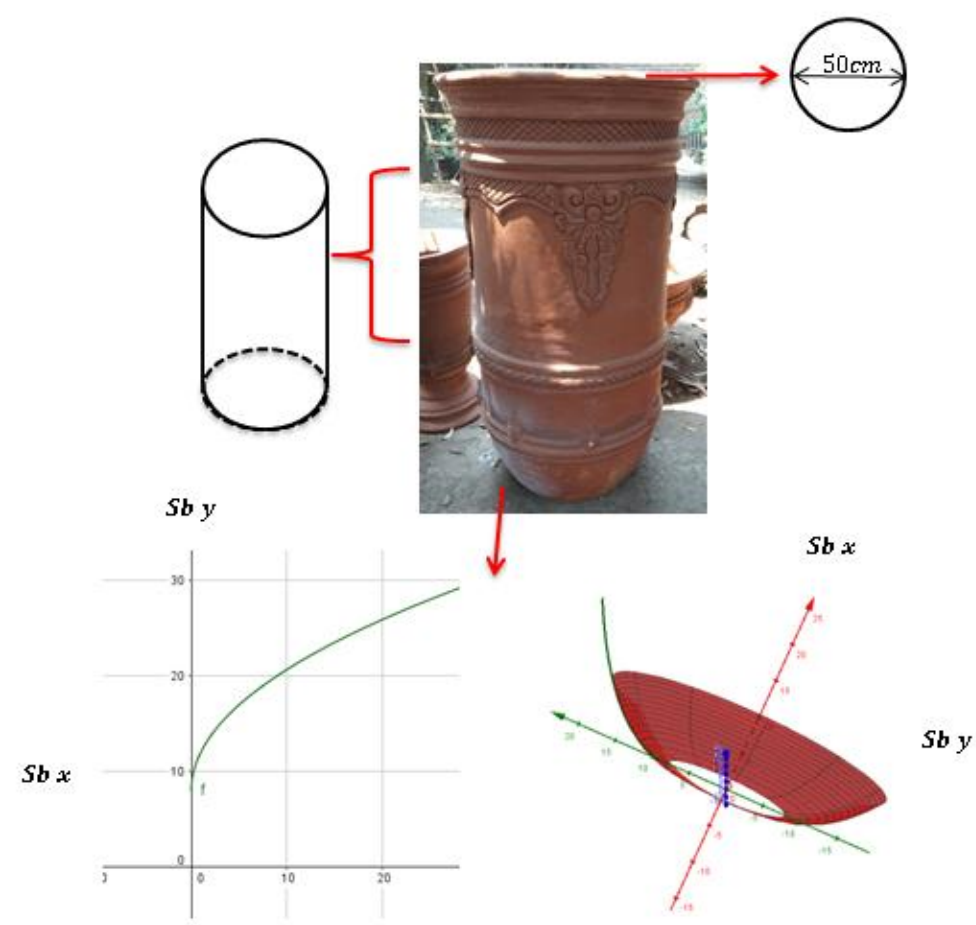

Gambar 15. Pot bunga ukuran diameter $50 \mathrm{~cm}$ dan tinggi $120 \mathrm{~cm}$ dan hasil sketsa geogebra

Gerabah yang berukuran besar dengan ukuran diameter $50 \mathrm{~cm}$ dan tinggi $120 \mathrm{~cm}$ biasanya dibuat dengan cara manual menggunakan teknik putar. Bagian yang dibuat pertama adalah cangkiran atau bagian bawah gerabah, kemudian dilanjutkan dengan menambah tanah sedikit demi sedikit hingga membentuk badan gerabah, kemudian ditambah lagi dengan tanah sehingga membentu bibir gerabah. gerabah dengan ukuran besar seperti ini biasanya dipesan untuk dijadikan pot Bungan, dan ditempatkan di depan villa. Berdasarkan pernyataan Kristanto(2014) dan Downing(2009) hasil penelitian menunjukkan bahwa setiap cangkiran atau bagian bawah gerabah pasti berbentuk kurva parabola, dan menunjukkan bahwa untuk setiap gerabah yang berukuran besar, badan dari gerabah tersebut selalu memiliki bentuk tabung atau silinder. Berdasarkan hasil penelitian dan teori yang ada bentuk pot bunga besar terdiri dari gabungan antara kurva parabola, tabung, dan lingkaran.

Pak Ngataji juga membuat peralatan dapur seperti tempat gula dan garam. Ukuran diameternya $7 \mathrm{~cm}$, tempat gula ini memiliki tutup. bentuk tempat gula ini menyerupai bola yang diiris bagian atas dan bawahnya. Cara membentuk tutup dari kendi kecil ini agar pas, pak Ngataji mengatakan bahwa saat membuat penutup kendi agar pas, yaitu dengan mengurangi ukurannya.

Tempat gula dan garam ini dapat dijadikan bahan ajar pada pembelajaran matematika yaitu konsep lingkaran dan konsep bangun ruang bola seperti yang terlihat pada Gambar 16.

Downing(2009) mengatakan bahwa bola adalah bangun yang dibentuk dari himpunan titik pada dimensi 3 yang mempunyai jarak yang sama terhadap satu titik (yang disebut titik pusat). Hasil penelitian menunjukkan bahwa bentuk dari gerabah tempat gula tersebut bulat seperti bola dengan ukuran kecil. Berdasarkan hasil penelitian dan teori yang terkait dapat dilihat bahwa bentuk dari 
tempat gula tersebut nyerupai bola namun diiris bagian atas dan bawahnya untuk alas dan tutup dari tempat gula tersebut.

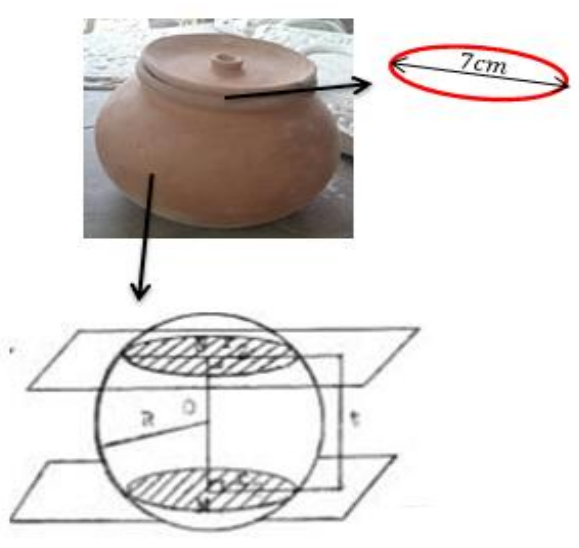

Gambar 16. Tempat gula dan hasil sketsa

Gambar dibawah ini adalah pot khusus untuk bunga teratai. Dengan diameter $70 \mathrm{~cm}$ dan tinggi $30 \mathrm{~cm}$. Untuk mempercantik pot ini juga dihiasi dengan ukiran-ukiran yang menarik.

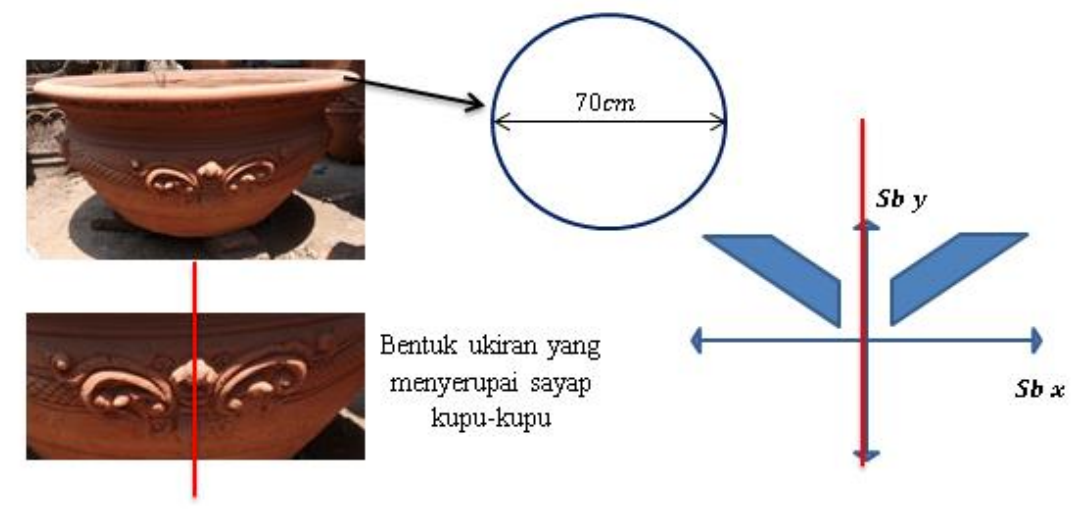

Gambar 17. Gambar pot bunga teratai dan hasil sketsa geogebra

Pot bunga teratai ini dapat dijadikan bahan ajar pembelajaran matematika pada konsep lingkaran dan konsep transformasi refleksi seperti yang dapat dilihat pada Gambar 17.

Budiarto(2006) mengatakan refleksi adalah cerminan dari suatu objek dengan jarak dan ukuran yang sama. Ukiran yang terdapat pada pot bunga teratai ini juga membentuk suatu refleksi jika ditari sebuah gari tepat ditengah-tengah ukiran. Susanah(2014) mengatakan lingkaran adalah himpunan semua titik di bidang datar yang berjarak sama dari suatu titik tetap di bidang tersebut. Hasil eksplorasi menunjukkan bahwa bibir pot bunga teratai ini memiliki bentuk lingkaran dengan ukuran diameter $70 \mathrm{~cm}$. Berdasarkan hasil penelitian dan teori yang terkait, dalam pot bunga teratai ini terdapat konsep matematika lingkaran dan transformasi geometri refleksi. Untuk hiasan pak

Ngataji biasanya membuat guci dengan ukuran tinggi $2 \mathrm{~m}$. Guci di bawah ini terdiri dari cangkiran bawah, badan guci, leher guci, dan bibir guci. Bibir guci memiliki diameter $25 \mathrm{~cm}$, kemudian leher guci memiliki bentuk tabung. Badan guci berbentuk seperti telur. Dan kemudian cangkiran bawah seperti kurva parabola terbuka keatas seperti yang dapat dilihat pada Gambar 18 . 

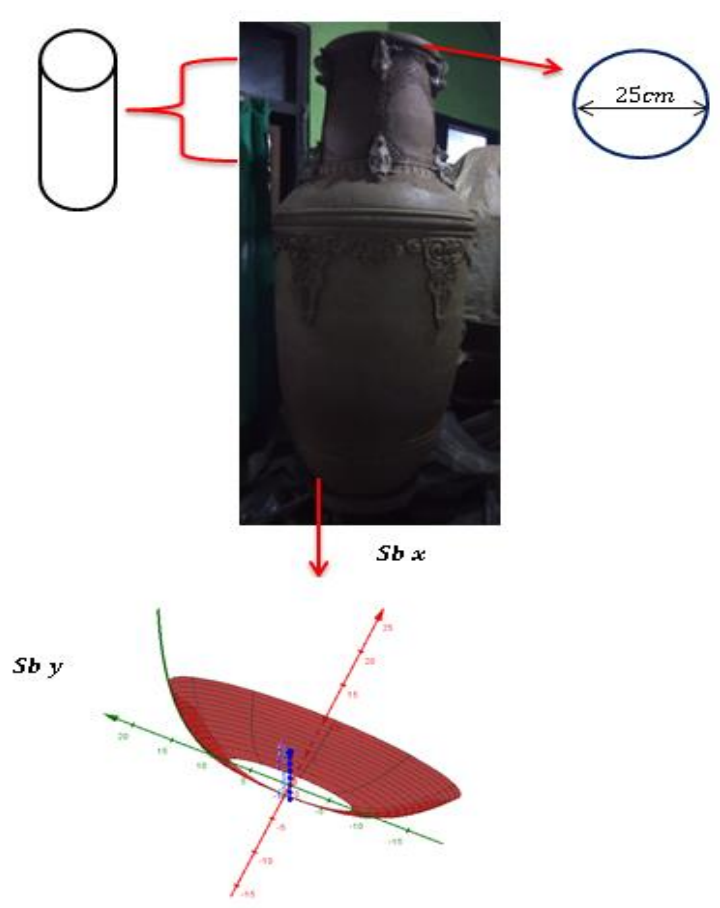

\section{Gambar 18. Guci Setinggi $2 m$ Dan Hasil Sketsa Geogebra}

Seperti yang dikatakan Susanah(2014) mengatakan lingkaran adalah himpunan semua titik di bidang datar yang berjarak sama dari suatu titik tetap di bidang tersebut. Downing(2009) mengatakan bahwa tabung adalah bangun yang dibentuk oleh gabungan semua ruas garis yang menghubungkan titik pada dua lingkaran yang kongruen dimana kedua lingkaran tersebut sejajar. Budiarto(2006) mengatakan bahwa refleksi adalah cerminan dari suatu objek dengan jarak dan ukuran yang sama. Kristanto(2014) mengatakan bahwa kurva parabola terbentuk dari irisan sebuah kerucut. Berdasarkan hasil penelitian dan teori yang terkait guci ini dapat dijadikan bahan ajar matematika pada konsep lingkaran, selain itu juga dapat diajarkan dalam konsep bangun ruang sisi lengkung yaitu tabung, dan juga dapat dijadikan bahan ajar matematika untuk konsep fungsi kurva parabola.

Ukiran pada gerabah juga banyak yang mengandung unsur matematika dan dapat dijadikan sebagai bahan ajar dalam pembelajaran matematika seperti yang terdapat pada Gambar 19.

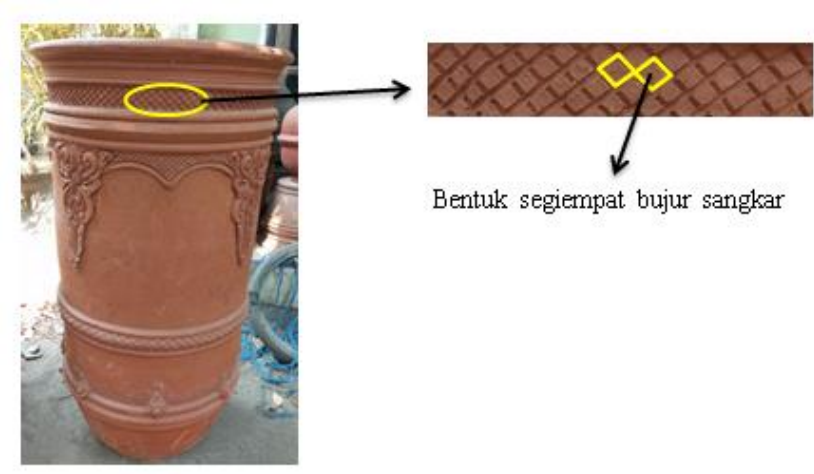

Gambar 19. Ukiran Pada Gerabah

Ukiran yang ada pada gerabah dapat dijadikan bahan ajar metematika konsep bangun datar segiempat dan juga konsep transformasi geometri translasi seperti pada Gambar 20. 


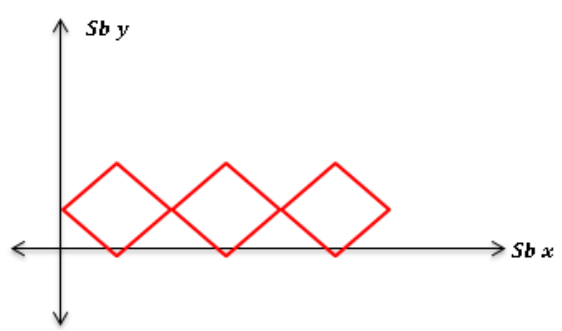

\section{Gambar 20. Hasil Sketsa Geogebra}

Mulyati(2010) mengatakan bahwa belah ketupat adalah jajar genjang dengan sisi-sisi yang berdekatan kongruen. Hasil dari pengamatan pada ukiran gerabah terdapat bentuk dari bangun datar segiempat yaitu belah ketupat. Budiarto(2006) mengatakan translasi adalah sebuah jenis transformasi yang memindahkan suatu titik sepanjang garis lurus dengan arah dan jarak. Hasil pengamatan ukiran gerabah menunjukkan bahwa bentuk dari belah ketupat tersebut diulang-ulang. Berdasarkan hasil penelitian dan teori-teori yang ada. Bentuk ukiran pada gerabah menerapkan konsep bangun datar segiempat dan konsep transformasi geometri translasi.

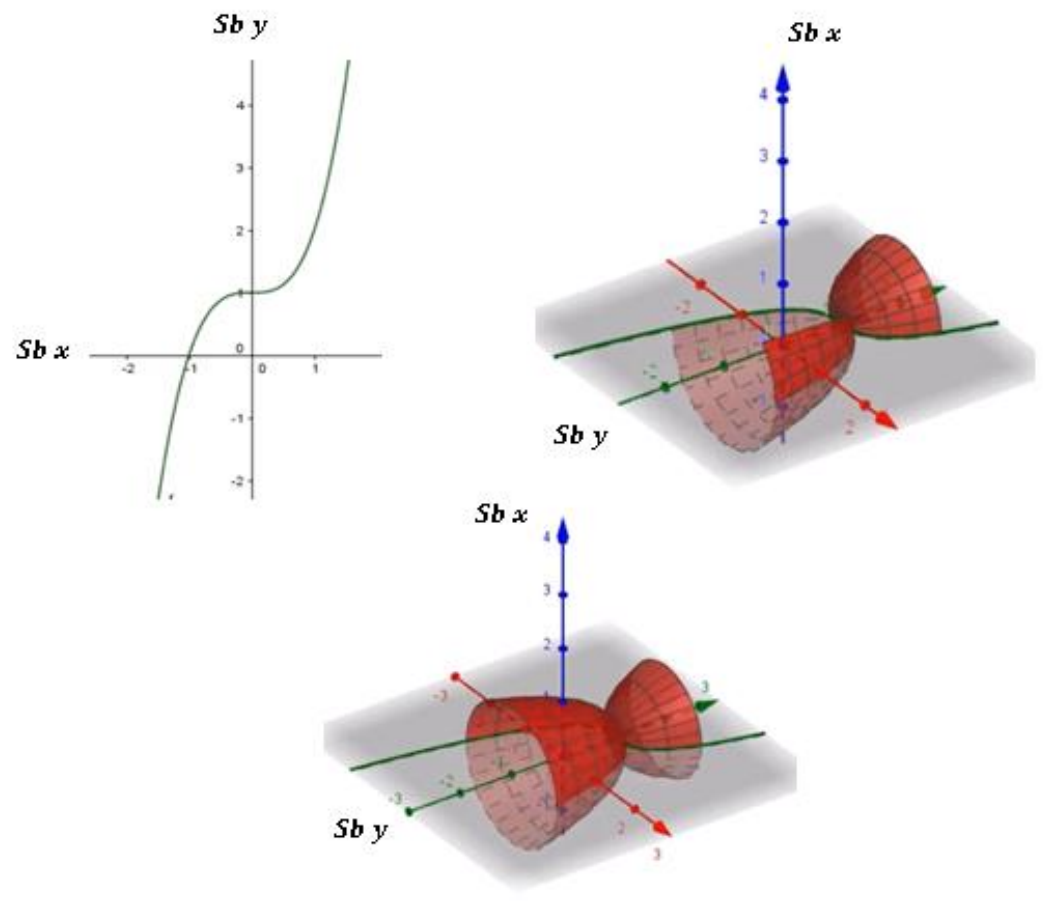

Gambar 21. Hasil Sketsa Gerabah Dengan Geogebra

Bentuk dari gerabah yang dibuat oleh pak Ngataji dapat juga disketsa dengan aplikasi geogebra. Sketsa ini adalah sketsa dari benda putar seperti yang terlihat pada Gambar 21.

Irawan(2017) mengatakan bahwa volume benda putar adalah volume yang diperoleh dari sebuah luasan yang diputar dengan proses putar tertentu (sumbu $x$ atau sumbu y). Hasil penelitian menunjukkan bahwa semua bentuk gerabah dapat disketsa dan dijadikan suatu liasan kemudian diputar terhadap sumbu x atau sumbu $y$. Berdasarkan hasil penelitian dan teori yang ada semua 
bentuk gerabah dapat dijadikan sebagai media pembelajaran matematika yang mengacu pada permasalahan sehari-hari yaitu dengan konsep volume benda putar.

\section{KESIMPULAN}

Hasil eksplorasi konsep matematika pada gerabah Mlaten berbentuk fisik dari konsep matematika lingkaran dan bangun ruang sisi lengkung yaitu bangun lingkaran, silinder, tabung, dan volume benda putar. Ukuran diameter dan tinggi gerabah berubah-ubah tergantung dari bentuk benda. Sedangkan untuk cobek ukuran keliling lingkarannya akan selalu sama sesuai dengan ukuran dari masing-masing tipe. Konsep-konsep matematika yang terdapat pada gerabah Mlaten adalah konsep lingkaran, konsep transformasi geometri, konsep bangun datar, konsep bangun ruang sisi lengkung, konsep fungsi, dan konsep volume benda putar. Konsep matematika yang terdapat di gerabah Mlaten dapat dijadikan bahan ajar berbasis budaya bagi guru, dan siswa juga akan lebih mudah memahami matematika dalam kehidupan sehari-hari.

Hasil eksplorasi yang berupa konsep bangun datar, transformasi, bangun ruang sisi lengkung, dan volume benda putar pada gerabah Mlaten dapat dimanfaatkan oleh guru sebagai sumber belajar matematika, karena objek etnomatematika yang ada disekitar lingkungan kita dapat dimanfaatkan untuk melaksanakan pembelajaran inovatif. Untuk selanjutnya dapat dilakukan eksplorasi tentang konsep matematika pada ukiran gerabah. Selain itu perlu dikembangkan penelitian tentang perangkat pembelajaran matematika berbasis budaya gerabah.

\section{DAFTAR PUSTAKA}

Bishop, A. J. (1994). Cultural Conflicts in the Mathematics Education of Indigenous People. Clyton, Victoria: Monash University.

Budiarto M.T, S. R. (2019). Ethnomatematika Budaya Jawa Timur.

Budiarto, M. T. (2006). Geometri Transformasi. Surabaya: Unesa University Press.

Budiarto, M. T. (n.d.). Ethnomatematika Budaya j.

Cimen, A. O. (2014). Discussing Ethnomathematics: Is mathematics culturally dependent? Istanbul, Turkey: ERPA.

D'Ambrosio, U. (1985). Ethnomathematics and its place in the history and pedagogy of mathematics. In F. t. mathematics.

Endraswara, S. (2018). Antropologi Sastra Lisan: Prospektif, Teori, dan Praktik Pengkajian. Jakarta: Yayasan Pustaka Obor Indonesia.

Fouze, A. Q. (2018). Development of Mathematics Thinking through Integration of Ethnomathematics Folklore Game in Mth Instruction. EURASIA Journal of Ethnomathematics, Science and Tecnology Education, 14(2): 617-630.

Gerdes, P. (1994). Reflection on Mathematics. For the .

Gerdes, P. (1994). Reflections on Mathematics. For the Learning of Mathematics, 14(2): 19-22.

Hardiarti, S. (2017). Etnomatematika: Aplikasi Bangun Datar Segiempat Pada Candi Muaro Jambi. 
Aksioma, Vol. 8, No. 2, e-ISSN 2579-7646.

Hiebert J, \&. C. (1992). Learning With Understanding. New York: Macmillan.

Keesing, R. M. (2010). Antropologi Budaya Suatu Prespektif Kontemporer. Jakarta: Erlangga.

Knijnik, G. (1997). An Ethnomathematical Approach in Mathematical Education: A Matter of Political Power. New York: NY: SUNY.

Kristanto, Y. D. (2014, Mei 15). Pendidikan Matematika. Retrieved from yos3prens.com: https://yos3prens.wordpress.com

Lubis, S. I. (2018). Eksplorasi Etnomatematika Pada Alat Musik Gordang Sambilan. Edumatika Jurnal Riset Pendidikan Matematika, Vol. 1, No. 2.

Mega Teguh Budiarto, R. S. (2019). Ethnomatematika Budaya Jawa Timur.

Mulyati, S. (2010). Geometri Euclid (Individual Textbook). Malang: Universitas Negeri Malang.

Pixten. (1994). Ethnomathematics and its Practice. For the Learning of Mathematics, 14(2).

Reflections on Mathematics. (1994). For the Learning of Mathematics, 19-22.

Susanah, H. (2014). Geometri. Surabaya: Unesa University Press.

Wahyuni A, A. A. (2013, Nopember 9). Peran Etnomatematika dalam Membangun Karakter Bangsa. (A. A. Wahyuni A, Performer) Seminar Nasional Matematika dan Pendidikan Matematika, Yogyakarta, DI Yogyakarta, Indonesia. 